\title{
Psychosocial characteristics of alcoholic and non-alcoholic liver disease recipient candidates in liver transplantation: a prospective observational study
}

\author{
Masato Shizuku, ${ }^{1,}$, Hiroyuki Kimura ${ }^{3^{*}}$ (D), Hideya Kamei ${ }^{1}$, Shinichi Kishi ${ }^{3}$, Tatsuya Tokura ${ }^{3}$, Nobuhiko Kurata $^{1}$, \\ Kanta Jobara ${ }^{1}$, Atsushi Yoshizawa ${ }^{1}$, Chisato Tsuboi ${ }^{4}$, Naoko Yamaguchi ${ }^{4}$, Midori Kato ${ }^{3}$, Keita Kawai ${ }^{3}$, \\ Makoto Yamashiki ${ }^{3}$, Emi Kanai ${ }^{3}$, Kanako Ishizuka ${ }^{3}$, Norio Ozaki ${ }^{3}$ and Yasuhiro Ogura ${ }^{1}$
}

\begin{abstract}
Background: There are long-standing controversies about the transplant indications for alcoholic liver disease (ALD), because of the recognition that ALD is fundamentally self-inflicted. However, it is unclear whether psychosocial characteristics of ALD are different from that of non-alcoholic liver disease (NALD) in the selection of liver transplantation (LT) recipients. We aimed to clarify the psychosocial characteristics of ALD recipients (ALD-R)/ALD recipient candidates (ALD-RC) and NALD recipients (NALD-R)/ NALD recipient candidates (NALD-RC).

Methods: From 2011 to 2019, 75 patients were enrolled in this prospective observational study (ALD-RC, $n=19$; NALD-RC, $n=56$ ), LT were carried out as follow; ALD-R, $n=6$; NALD-R, $n=52$. We evaluated psychosocial characteristics in the preoperative period and 3,12 months after LT (ALD-R, $n=3 / 3$; NALD-R, $n=28 / 25$ ). The following scales were used to evaluate psychosocial characteristics: Visual Analogue Scale, Alcohol Use Disorders Identification Test, Hospital Anxiety and Depression Scale, Beck Depression Inventory, Brief Evaluation of Medication Influences and Beliefs, Social Support Questionnaire (SSQ), Temperament and Character Inventory, Parental Bonding Instrument (PBI), the Short Form Health Survey (SF-36).

Results: When evaluating on the basis of abstinence rule, a comparison of ALD-RC and NALD-RC in the preoperative period identified similar patterns of psychosocial characteristics, except that the NALD-RC scored higher on the PBI item "overprotection from mother" $(P<0.05)$. The only significant difference between ALD-R and NALD-R after liver transplantation was in SSQ scores at 3 months.

Conclusion: The psychosocial characteristics of ALD-RC and NALD-RC may be similar when evaluated on the basis of Japan's abstinence rule. This result also imply that the psychosocial characteristics of ALD-RC may differ from the previously reported psychosocial characteristics of alcohol dependent patients. These findings have the potential to provide helpful information for the evaluation of ALD-RC.
\end{abstract}

\footnotetext{
*Correspondence: kimurahi@med.nagoya-u.ac.jp

${ }^{3}$ Department of Psychiatry, Nagoya University Graduate School

of Medicine, 65 Tsurumai-cho, Showa-ku, Nagoya 466-8550, Japan

Full list of author information is available at the end of the article
}

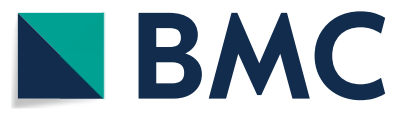

C The Author(s) 2021. Open Access This article is licensed under a Creative Commons Attribution 4.0 International License, which permits use, sharing, adaptation, distribution and reproduction in any medium or format, as long as you give appropriate credit to the original author(s) and the source, provide a link to the Creative Commons licence, and indicate if changes were made. The images or other third party material in this article are included in the article's Creative Commons licence, unless indicated otherwise in a credit line to the material. If material is not included in the article's Creative Commons licence and your intended use is not permitted by statutory regulation or exceeds the permitted use, you will need to obtain permission directly from the copyright holder. To view a copy of this licence, visit http://creativecommons.org/licenses/by/4.0/. The Creative Commons Public Domain Dedication waiver (http://creativeco mmons.org/publicdomain/zero/1.0/) applies to the data made available in this article, unless otherwise stated in a credit line to the data. 
Keywords: Liver transplantation, Alcoholic liver disease, Alcohol dependence, Psychosocial functioning, Personality, Social support

\section{Background}

Liver transplantation for alcoholic liver disease involves many issues, such as the validity of the 6-month abstinence rule [1-3], indications regarding liver transplantation for acute alcoholic hepatitis [4-6] and alcohol relapse $[7,8]$. In particular, the importance of psychosocial evaluation before and after liver transplantation to prevent alcohol relapse has been emphasized $[9,10]$. It is generally assumed that patients with alcoholic liver disease have previously experienced alcoholic dependence. Therefore, it is very important to manage alcohol relapse in patients who have undergone liver transplantation for alcoholic liver disease. Previous research has shown that postoperative psychological intervention reduces the risk of alcohol relapse after liver transplantation [11-14].

There may be some distinctive problems such as preconceptions that patients with alcohol dependence or alcohol-related diseases are weak-willed. Indeed, we tend to consider those who have received a liver transplant for alcoholic liver disease as alcohol-dependent patients who also have other addictions, depression, and alcohol-related problems. However, the alcohol relapse rate among liver transplant recipients who had alcoholic liver disease is approximately $30-40 \%[2,15$, $16]$, whereas this rate is approximately $60-70 \%$ among alcohol dependent patients $[11,12]$. Despite this evidence, we may be not able to completely distinguish alcoholic liver disease from alcohol dependence when evaluating candidates for liver transplantation for alcoholic liver disease.

There have been many studies on psychosocial evaluations for liver transplant recipients; however, it is unclear whether psychosocial characteristics differ between alcoholic liver disease recipient candidates (ALD-RC) and non-alcoholic liver disease recipient candidates (NALD-RC). To our knowledge, no previous reports have examined such differences in psychosocial characteristics. This study aimed to clarify the psychosocial characteristics of ALD-RC and to inform the appropriate selection of liver transplant recipient candidates.

We performed a prospective observational study that focused on the following three points. First, we compared the psychosocial characteristics of ALD-RC and NALD-RC before liver transplantation on the basis of current abstinence rule in Japan. Second, we evaluated psychosocial characteristics consecutively in alcoholic liver disease recipient (ALD-R) and non-alcoholic liver disease recipient (NALD-R) patients who actually received a liver transplant at 3 and 12 months after liver transplantation. Third, we compared scores on the Medical Outcomes Study 36-Item Short Form Health Survey (SF-36) between ALD-R and published Japanese norms at 3 and 12 months after liver transplantation.

\section{Methods}

\section{Study population and data collection}

In this prospective observational study, we enrolled 75 liver transplant recipient candidates aged 16 years or older (ALD-RC, $\mathrm{n}=19$; NALD-RC, $\mathrm{n}=56$ ) who were referred to our hospital from January 2011 to December 2019. The recipient candidates in this study were patients who met the physical criteria for liver transplantation based on the ethical guidelines of the Japan Society for Transplantation $[17,18]$.

\section{The selection process for liver transplant candidates}

To conduct appropriate assessment of indications for liver transplantation, our center created a transplantation medical team in 2004. This team comprises transplant surgeons, gastroenterologists, hepatologists, psychiatrists, transplant coordinators, and psychologists. When patients are referred to our hospital, transplant surgeons, gastroenterologists, and hepatologists evaluate whether they meet the indication for liver transplantation such as primary liver disease, blood tests, model for end-stage liver disease score, within Milano criteria and ChildPugh classification C. In Japan, the transplantation criteria about alcohol use disorder indicates that absolute contraindication only for alcohol use disorders without 6 months of sobriety (changed to 18 months after March 2014), therefore, ALD-RC are required to have followed a 6-month abstinence rule at the initial assessment. Following physical evaluation, transplant coordinators check their family situation and support system. Psychiatrists and psychologists check psychosocial characteristics, namely performance on the Visual Analogue Scale (VAS), Alcohol Use Disorders Identification Test (AUDIT), Hospital Anxiety and Depression Scale (HADS), Beck Depression Inventory (BDI), Brief Evaluation of Medication Influences and Beliefs (BEMIB), Social Support Questionnaire (SSQ; Number of Persons, NP; Satisfaction Rating, SR), Temperament and Character Inventory (TCI), Parental Bonding Instrument (PBI), and the Medical Outcomes Study 36-Item Short Form Health Survey 
(SF-36; Physical Component Summary, PCS; Mental Component Summary, MCS).

\section{Postoperative follow-up of liver transplant recipients}

The team continues to hold interdisciplinary conferences every week to share patient information [10]. After liver transplantation, all patients received ongoing support from psychiatrists and psychologists and, in cases of comorbid psychiatric disorders, received psychiatric treatment such as pharmacotherapy or psychotherapy.

\section{The aim in this study}

In this study, we conducted the following three investigations. First, on the basis of current abstinence rule in Japan, we compared psychosocial characteristics, namely scores on the VAS, AUDIT, HADS, BDI, BEMIB, SSQ (NP/SR), TCI, PBI, and SF-36 (PCS/MCS), between ALD$\mathrm{RC}$ and NALD-RC before liver transplantation. Second, we evaluated psychosocial characteristics, namely scores on the VAS, AUDIT, HADS, BDI, BEMIB, SSQ (NP/SR), SF36 (PCS/MCS), at the preoperative period and at 3 and 12 months after liver transplantation for patients who received liver transplantation. Third, we compared SF-36 scores between ALD-R and published Japanese norms at 3 and 12 months after liver transplantation. Japanese norms were obtained from data reported by Fukuhara et al., "Manual of SF-36 Japanese version 1.2" [19-21].

Although we cannot rule out selection bias, we hoped to avoid this as much as possible by identifying all patients diagnosed within a specific period of time.

\section{Measurements}

The VAS assesses subjective characteristics or attitudes that cannot be directly measured. Scores range from 0 to 100 points $[22,23]$. We measured pain in this study. The AUDIT is a measurement tool to screen patients for possible alcoholism. The AUDIT comprises a 10-item questionnaire and is a simple and useful method for early detection of harmful alcohol use [24]. The HADS scale assesses levels of anxiety and depression. The Japanese version of the HADS questionnaire was used to assess patients' depression severity [25, 26]. Higher scores indicate more severe symptoms. The BDI is a self-rating measurement tool developed by Beck et al.; it has high diagnostic utility for depression [27, 28]. The BEMIB was developed to identify non-adherence in patients with psychiatric disorders and consists of an 8-item scale. In this study, we used the Japanese version of the BEMIB [29]. The SSQ measures social support and satisfaction with social support from the perspective of the interviewee. The SSQ consists of two subscales: the Number of Persons (NP) subscale, which reflects the sum of the perceived number of others who provide social support, and the Satisfaction Rating (SR) subscale, which reflects the sum of the individual's degree of satisfaction with perceived social support. In this study, the six-item Japanese version of the SSQ was used [30, 31]. The TCI assesses personality characteristics. According to Cloninger [32, 33], personality can be divided into temperament (Novelty Seeking, Harm Avoidance, Reward Dependence, Persistence) and character domains (Self-directedness, Cooperativeness, Self-transcendence). Participants respond to each TCI item by answering "true" or "false" and a total score for each temperament and character dimension is calculated. In this study, we used the Japanese version of the TCI [34]. The PBI assesses perceived rearing [35]. The PBI is a self-report questionnaire that evaluates a person's perception of how they were raised by asking the respondent to recall their parents' childrearing attitudes before the age of 16 years. The PBI consists of four categories: paternal care, paternal overprotection, maternal care, and maternal overprotection, and scores are obtained for each category. In this study, we used the Japanese version of the scale [36]. The SF36 is a 36-item patient-reported survey of patient health. Administration of the SF-36 generates a health profile on eight domains: general health, physical function, role physical, bodily pain, vitality, social functioning, mental health, and role emotional. The SF-36 also provides two higher-order summary scores: the physical component summary (PCS) and the mental component summary (MCS). Scores for each summary range from 0 to 100 . Higher scores indicate better health-related quality of life [37]. Published Japanese norms were used as a comparison for SF-36 scores. We compared recipients' health as measured by the SF-36 with national standards using these norms [19-21].

\section{Statistical analysis}

Statistical analyses were performed using SPSS, version 25 (IBM, Armonk, NY, USA). Continuous variables were compared by $t$ test and Mann-Whitney U test.

Homogeneity of variance was evaluated using Levene's test. For between-group comparisons, Student's t-test was used if the data showed homogeneity of variance. In the absence of homogeneity of variance, Welch's method was used. The chi-square test was used to examine differences between categorical variables. A $P$-value of $<0.05$ was regarded as statistically significant. We did not determine an a priori sample size; owing to the small pool of study subjects, we conducted the analysis using the maximum sample size available. We compensated by checking the effect size after the analysis. Because of the exploratory nature of this study, we did not adjust for multiple comparison issues. A statistical review of the study was performed by a biomedical statistician. Because of the 


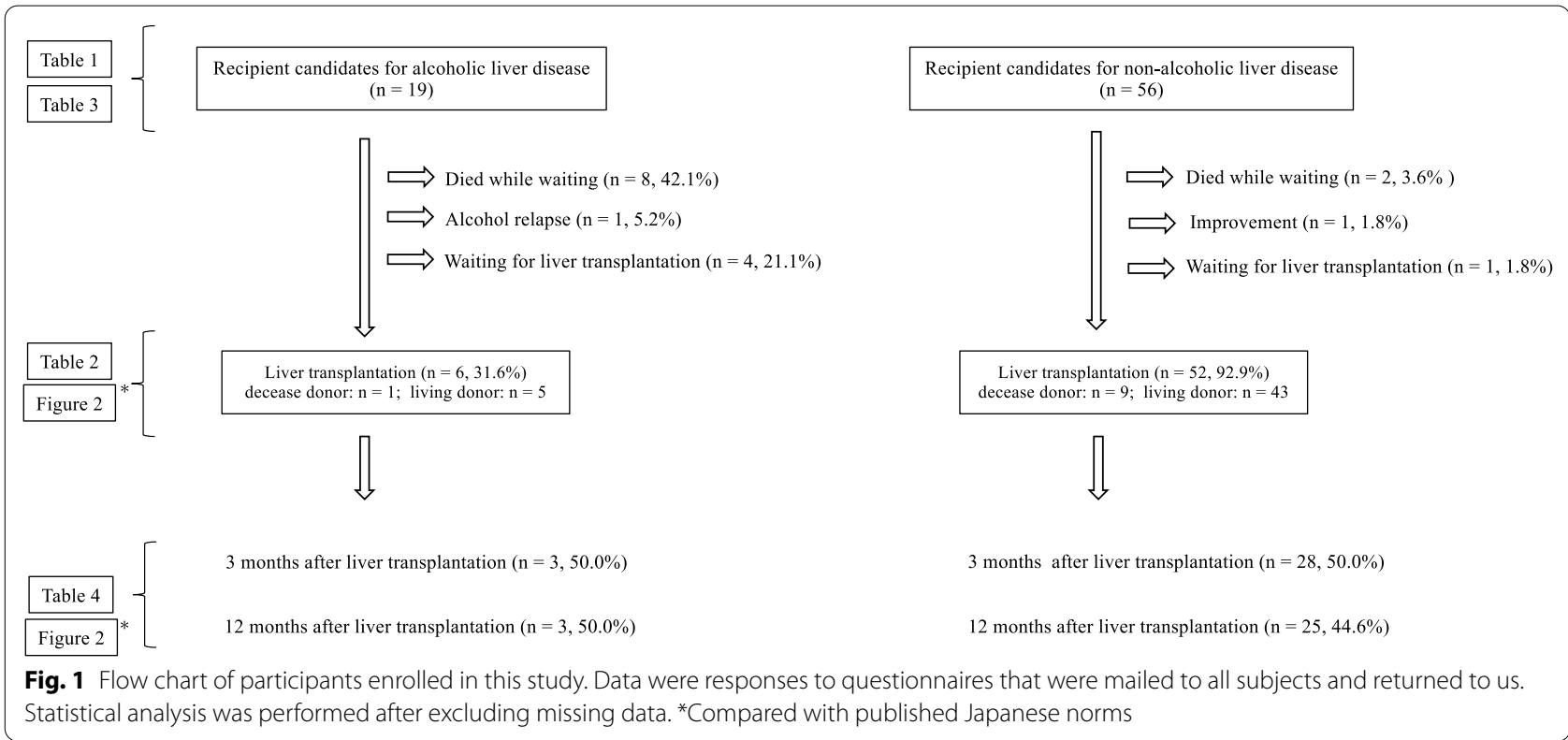

exploratory nature of this study, we did not adjust for multiple comparison issues. A statistical review of the study was performed by a biomedical statistician.

\section{Results}

The ALD-RC who met the physical criteria for liver transplantation were 76 patients at initial assessment, however, 19 patients were evaluated because 57 patients were excluded as ALD-RC by pre-liver transplantation evaluation (Shortage of absent drinking or fail to quit drinking; 32, Improvement of liver function after initial evaluation; 2, Drop-out of follow-up before liver transplantation; 2, Withdraw offer for liver transplantation; 2, Transfer to other hospital; 2, Development of other diseases; 1, Unknown; 16). Additionally, in the 76 ALD-RC who met the physical criteria, 27 patients were applied the 18-month abstinence rule (before February 2014) and 49 patients were the 6-month abstinence (after March 2014). Finally, as shown in Fig. 1, there were 19 and 56 evaluable patients in the ALD-RC and NALD-RC groups, respectively. Of the 19 ALD-RC, six (31.6\%) actually underwent liver transplantation (living donor liver transplantation: 5; deceased donor liver transplantation: 1), eight (42.1\%) died waiting for a transplant, one $(5.2 \%)$ experienced alcohol relapse, and four (21.1\%) continued to wait for liver transplantation. One patient was excluded from liver transplantation because of alcohol relapse. This patient was a 38-year-old man who had been treated for alcoholic cirrhosis for 5 years. On physical and psychosocial evaluation, he appeared to meet the evaluation criteria for liver transplantation but was subsequently found to have had a small number of alcohol relapses, which prompted a reevaluation. This man did not receive support from a psychiatrist or psychologist before liver transplantation because he lived far away from the studies hospital. Of the 56 NALD-RC, 52 (92.9\%) actually underwent liver transplantation (living donor liver transplantation: 43, deceased donor liver transplantation: 9), two (3.6\%) died waiting for a transplant, one (1.8\%) experienced improvement, and one $(1.8 \%)$ was still waiting for liver transplantation. The numbers of patients evaluated at 3 months after liver transplantation in the ALD-R and NALD-R groups were 3 and 28 patients, respectively. At 12 months after liver transplantation, three ALD-R and 25 NALD-R were evaluated.

The demographic characteristics of the ALD-RC and NALD-RC groups are shown in Table 1. There was no significant difference in any of the variables. History of psychiatric disorders also showed no significant differences between ALD-RC and NALD-RC. The primary diseases experienced by the ALD-RC are shown in Table 2 . The perioperative characteristics of the ALD-R and NALD-R who underwent liver transplantation are shown in Table 3. There was no significant difference between the two groups in any of the variables.

The comparison of psychosocial characteristics in the ALD-RC and NALD-RC groups before liver transplantation is shown in Table 4. The only significant betweengroup difference was for "overprotection from mother"; the NALD-RC group scored higher on this characteristic.

Table 5 shows the results of the between-group comparisons in scores on the VAS, AUDIT, HADS, BDI, BEMIB, SSQ (NP/SR), and SF-36 (PCS/MCS) at 3 and 12 months after liver transplantation for ALD-R and 
Table 1 Demographic characteristics of the ALD-RC and NALD-RC groups

\begin{tabular}{llll}
\hline Variables & ALD-RC group $(\boldsymbol{n}=\mathbf{1 9})$ & NALD-RC group $(\boldsymbol{n}=\mathbf{5 6})$ & $\boldsymbol{P}$-value \\
\hline Age (mean years, range) & $47.7(37-60)$ & $46.8(16-67)$ & 0.82 \\
Sex (Male/Female) & $11 / 8$ & $26 / 30$ & 0.29 \\
AST (IU/L) (mean, SD) & $52.1(28.1)$ & $247.8(1085.0)$ & 0.44 \\
ALT (IU/L) (mean, SD) & $27.8(15.0)$ & $184.6(763.5)$ & 0.39 \\
Hepatic encephalopathy (point, mean, SD) & $1.2(0.4)$ & $1.3(0.5)$ & 0.25 \\
Ascites (point, mean, SD)) & $1.8(0.8)$ & $2.0(0.9)$ & 0.48 \\
Total Bilirubin (mg/dL) (mean, SD) & $7.7(7.3)$ & $8.6(10.9)$ & 0.76 \\
Albumin (g/dL) & $2.9(0.5)$ & $2.8(0.7)$ & 0.58 \\
Prothrombin time (\%) (mean, SD) & $46.5(17.2)$ & $57.1(20.9)$ & 0.10 \\
PT-INR (mean, SD) & $1.61(0.4)$ & $1.51(0.6)$ & 0.69 \\
Creatinine (mg/dL) (mean, SD) & $0.84(0.4)$ & $1.07(1.3)$ & 0.49 \\
MELD score (point) (mean, SD) & $18.1(6.2)$ & $9.9(2.3)$ & 0.93 \\
Child-Pugh score (point) (mean, SD) & $10.3(1.7)$ & & 0.55 \\
Primaryliver disease & & $5(8.9)$ & 0.11 \\
Number of HCC (\%) & $5(26.3)$ & $25 / 31$ & 0.85 \\
Psychiatric disorders (Present/Absent) & $8 / 11$ & \\
\hline
\end{tabular}

ALD-RC: Alcoholic liver disease recipient candidate; ALT: Alanine transaminase; AST: Aspartate transaminase; HCC: Hepatocellular carcinoma; NALD-RC: Non-alcoholic liver disease recipient candidate; MELD: Model for end-stage liver disease score; PT-INR: International normalized ratio of prothrombin time; SD: Standard deviation

Table 2 The primary disease of the ALD-RC and NALD-RC

\begin{tabular}{lll}
\hline & $\begin{array}{l}\text { ALD-RC } \\
(\mathbf{n}=\mathbf{1 9})\end{array}$ & $\begin{array}{l}\text { NALD-RC } \\
(\mathbf{n}=\mathbf{5 6})\end{array}$ \\
\hline Primary liver disease & & \\
Alcoholic liver cirrhosis & 14 & 0 \\
Alcoholic liver cirrhosis with HCC & 5 & 0 \\
Primary sclerosing cholangitis & 0 & 9 \\
Primary biliary cholangitis & 0 & 8 \\
Biliary atresia & 0 & 5 \\
Non-alcoholic steatohepatitis & 0 & 5 \\
Autoimmune hepatitis & 0 & 4 \\
Fulminant hepatitis & 0 & 4 \\
Hepatic C virus related cirrhosis & 0 & 3 \\
Polycystic liver disease & 0 & 3 \\
Hepatic B virus related cirrhosis with HCC & 0 & 3 \\
Hepatic B virus related cirrhosis & 0 & 2 \\
Hepatic C virus related cirrhosis with HCC & 0 & 2 \\
Wilson disease & 0 & 1 \\
Hepatic fibrosis & 0 & 1 \\
Idiopathic portal hypertension & 0 & 1 \\
Congenital biliary dilatation & 0 & 1 \\
Hypoplastic right hepatic lobe & 0 & 1 \\
Unknown & 0 & 3 \\
\hline ALD-RC, Aloholc Liver Disease & & 3 \\
\hline
\end{tabular}

ALD-RC, Alcoholic Liver Disease Recipient Candidate; HCC, Hepatic Cell Carcinoma; NALD-RC, Non-Alcoholic Liver Disease Recipient Candidate

NALD-R. The only significant difference between the two groups was for SSQ (NP) score at 3 months after liver transplantation; the ALD-R group scored higher than the NALD-R group on the SSQ (NP). However, there were small number of patients in this result, especially in ALD-R group (3 months, ALD-R: 3, NALD-R; 28; 12 months, ALD-R: 3, NALD-R: 25). Therefore, although this result may be reference, caution is warranted in interpreting these results.

Figure 2 shows the comparison of SF-36 (PCS/MCS) scores between ALD-R and published Japanese norms. Although the PCS score in the ALD-R group was significantly lower than published Japanese norms preoperatively and 12 months after liver transplantation, there was no significant difference in MCS score at any time. These results indicate that the ALD-R had significantly poorer physical health compared with national standards, not only preoperatively but also 12 months after liver transplantation. In contrast, there was no significant betweengroup difference in mental health at any time.

\section{Discussion}

ALD is one of the indications for liver transplantation, and the psychosocial evaluation of patients with alcoholic liver disease is extremely important. However, it is unclear whether psychosocial characteristics differ between ALD-RC and NALD-RC. The present research is the first prospective observational study to examine the psychosocial characteristics of recipient candidates in detail. In this study, there were few psychosocial differences between ALD-RC and NALD-RC. These findings indicate that the psychosocial characteristics of ALD-RC and NAD-RC may be similar when evaluated 
Table 3 A comparison of perioperative characteristics for ALD-R and NALD-R groups

\begin{tabular}{|c|c|c|c|}
\hline Variables & ALD-R group $(n=6)$ & NALD-R group $(n=52)$ & $P$-value \\
\hline Age (mean, range) & $52.3(46-60)$ & $46.5(16-67)$ & 0.31 \\
\hline Sex (Male/Female) & $3 / 3$ & $24 / 28$ & 0.87 \\
\hline MELD score (point) (mean \pm SD) & $20.0 \pm 8.6$ & $17.9 \pm 10.6$ & 0.65 \\
\hline Operation time (min) (mean \pm SD) & $698 \pm 53$ & $757 \pm 157$ & 0.39 \\
\hline Blood loss (ml) & $10,615(4468)$ & $9295(8353)$ & 0.77 \\
\hline Donor type (Decease/Living) & $1 / 5$ & $9 / 43$ & 0.98 \\
\hline Graft type (left/right/whole) & $1 / 4 / 1$ & $4 / 40 / 8$ & 0.78 \\
\hline Blood type (identical/compatible/incompatible) & $5 / 0 / 1$ & $31 / 13 / 8$ & 0.37 \\
\hline Hospital stay (day) (mean, SD) & $79.0(37.7)$ & $83.1(79.9)$ & 0.90 \\
\hline Follow up period (day) (mean, range) & $1160(478-2150)$ & $1626(107-3874)$ & 0.25 \\
\hline \multicolumn{4}{|l|}{ Postoperative outcomes } \\
\hline Alive (\%) & $5(83.3)$ & $47(90.4)$ & 0.61 \\
\hline Dead (\%) & $1(16.7)$ & $5(9.6)$ & \\
\hline \multicolumn{4}{|l|}{ Postoperative complications } \\
\hline Clavien-Dindor classification Grade $\geq$ IIIb (\%) & $3(50.0)$ & $16(30.8)$ & 0.39 \\
\hline
\end{tabular}

ALD-R: Alcoholic liver disease recipient; MELD: Model for end-stage liver disease score; NALD-R: Non-alcoholic liver disease recipient; SD: Standard deviation

on the basis of Japan's abstinence rule. Moreover, the findings also imply that the psychosocial characteristics of ALD-RC may differ from the previously reported psychosocial characteristics of alcohol dependent patients, such as unfavorable maternal bonding [38, 39]. Therefore, there is a need to recognize these differences and evaluate ALD-RC after confirming whether an abstinence rule is applied or not.

Some medical workers have the preconception that alcohol-dependent patients are weak-willed and noncompliant and that their illness is self-inflicted. However, previous studies have reported a considerable difference in the rate of alcoholic relapse between liver transplant recipients with alcohol liver disease [2, $15,16]$ and alcohol-dependent patients [11, 12]. The present findings demonstrate almost identical psychosocial characteristics between the ALD-RC and NALD-RC groups when applying either the 6-month or the 18-month abstinence rule. There are five explanations for this similarity. First, the pre-referral of recipient candidates for liver transplantation by previous doctors may have resulted in a selection effect by excluding patients with very poor psychiatric symptom control. Second, the patients had a sufficient and enthusiastic family support system. Third, the patients' alcohol abstinence may have been prompted by others' expressions of disgust during their frequent treatment or hospitalization. Fourth, although the patients may have been heavy drinkers, they may not have been alcohol dependent. Fifth, alcohol dependence factors in ALD-RC may have been corrected through the abstinence rule. It is also possible that the psychosocial characteristics of ALD-R and NALD-RC may be similar, but we cannot conclude this because of the small sample size.

In this study, 57 of the 76 ALD-RC met the physical criteria, however, more than half of these patients (32 of 57) were excluded because of alcohol-related problems. Moreover, eight patients in the ALD-RC group died waiting for a transplant. In Japan, the 18-month abstinence rule for liver transplantation for alcoholic cirrhosis was applied through February 2014, and a 6-month abstinence rule has been used since March 2014. Without these abstinence rules, the patients in the ALD-RC group might have had more opportunities for liver transplantation. However, because the ALD-RC and NALD-RC were similar in terms of psychosocial characteristics, the length of abstinence rule in the present study may have made the psychosocial characteristics of the ALD-RC different from those typically seen with alcohol dependence, such as poor medication adherence or alcohol relapse $[2,15,16,40-42]$. In this study, it is unclear whether an abstinence rule is appropriate, but evaluators should consider the situation in terms of alcohol-related diseases and the number of donors in own country.

Notably, the social context of each county (e.g., alcoholdrinking behavior and the nature of the medical system) should be considered when interpreting the implications of this study. Previous studies in Western countries have reported that alcoholic liver disease is associated with parental neglect and abuse [40-42] and that acloholic liver disease is comorbid with certain psychiatric disorders [43]. Our study showed different results, finding no significant differences in psychosocial characteristics or 
Table 4 Comparison of psychosocial characteristics between ALD-RC group and NALD-RC group before liver transplantation

\begin{tabular}{|c|c|c|c|c|c|c|}
\hline Variables & $\begin{array}{l}\text { ALD-RC } \\
n=19 \\
\text { Mean (SD) }\end{array}$ & $\begin{array}{l}\text { NALD-RC } \\
n=56 \\
\text { Mean (SD) }\end{array}$ & $\mathbf{t}$ & df & $P$ & $\mathbf{r}$ \\
\hline VAS* & $14.28(18.32)$ & $15.52(20.52)$ & - & - & 0.87 & \\
\hline AUDIT & $3.67(6.06)$ & $1.65(3.62)$ & 1.64 & 62 & 0.11 & \\
\hline HADS & $9.83(7.51)$ & $9.60(6.59)$ & 0.12 & 58 & 0.90 & \\
\hline $\mathrm{BDI}$ & $11.44(9.49)$ & $9.07(7.11)$ & 1.07 & 59 & 0.29 & \\
\hline BEMIB & $28.33(5.49)$ & $28.44(4.80)$ & -0.07 & 45 & 0.95 & \\
\hline \multicolumn{7}{|l|}{ SSQ } \\
\hline NP & $4.11(1.84)$ & $4.82(2.97)$ & -0.94 & 60 & 0.35 & \\
\hline SR & $5.24(0.81)$ & $5.09(1.22)$ & 0.47 & 58 & 0.64 & \\
\hline \multicolumn{7}{|l|}{ TCl } \\
\hline Novelty Seeking & $8.63(2.73)$ & $8.10(2.57)$ & 0.67 & 53 & 0.50 & \\
\hline Harm Avoidance & $11.38(4.95)$ & $11.26(4.04)$ & 0.09 & 53 & 0.93 & \\
\hline Reward Dependence & $9.31(1.99)$ & $10.11(2.13)$ & -1.27 & 51 & 0.21 & \\
\hline Persistence & $2.24(1.92)$ & $2.78(1.53)$ & -1.03 & 25 & 0.31 & \\
\hline Self-Directedness & $14.19(4.46)$ & $16.09(5.14)$ & -1.27 & 47 & 0.21 & \\
\hline Cooperativeness & $17.47(3.63)$ & $18.42(3.21)$ & -0.98 & 53 & 0.33 & \\
\hline Self-Transcendence & $3.67(2.95)$ & $3.62(3.05)$ & 0.06 & 55 & 0.95 & \\
\hline \multicolumn{7}{|l|}{$P B \mid$} \\
\hline Care/Father & $15.31(8.20)$ & $11.97(9.62)$ & 1.22 & 53 & 0.23 & \\
\hline Over-protection/Father & $29.00(5.65)$ & $29.66(6.73)$ & -0.34 & 52 & 0.73 & \\
\hline Care/Mother & $12.94(8.34)$ & $8.08(9.31)$ & 1.90 & 56 & 0.06 & \\
\hline Over-protection/Mother & $23.41(7.39)$ & $28.71(7.69)$ & -2.39 & 53 & 0.02 & 0.31 \\
\hline \multicolumn{7}{|l|}{$S F-36$} \\
\hline PCS & $26.84(21.35)$ & $28.68(17.85)$ & -0.30 & 47 & 0.77 & \\
\hline MCS & $49.80(12.68)$ & $44.65(11.34)$ & 1.36 & 47 & 0.18 & \\
\hline
\end{tabular}

Bold value indicate $p<0.05$

ALD-RC: Alcoholic liver disease recipient candidate; AUDIT: Alcohol Use Disorders Identification Test; BDI: Beck Depression Inventory; BEMIB, Brief Evaluation of Medication Influences and Beliefs; HADS: Hospital Anxiety and Depression Scale; NALD-RC: Non-alcoholic liver disease recipient candidate; PBI: Parental Bonding Instrument; SF-36: Medical Outcomes Study 36-Item Short Form Health Survey (PCS: Physical Component Summary; MCS: Mental Component Summary); SSQ: Social Support Questionnaire (NP: Number of Persons; SR: Satisfaction Rating); TCl: Temperament and Character Inventory; VAS: Visual Analogue Scale

*Mann-Whitney t test was used to evaluate the differences between two groups

in history of psychiatric disorders between ALD-RC and NALD-RC at initial assessment. No previous studies have specially investigated this issue, but prior work has demonstrated that over-protection from supporters/ partners is more common in patients with physical diseases such as diabetes mellitus or myocardial infarction $[44,45]$. The paradoxical results in our study may have been caused by events such as those described above or by elements of Japan's unique social context. Additionally, as shown in Fig. 1, the percentage of patients who died while waiting for liver transplantation differed for ALD-RC (42.1\%) and NALD-RC (3.6\%). In Japan, approximately $85 \%$ of liver transplantations have been reported to be from living donors because of a lack of deceased donors [46]. Therefore, patients without potential donors in their families do not have the opportunity for liver transplantation. Because liver donation is voluntary, it is possible that fewer family members offered to serve as donors for patients in the ALD-RC group than for those in the NALD-RC group. Additionally, the Japanese transplantation criteria regarding alcohol use disorder may further reduce the chance of receiving liver transplantation from a deceased donor for those with alcoholic liver disease. Thus, the specific local contexts should be considered when interpretating this article.

In this study, we also compared the ALD-R group's performance with published Japanese norms for the PCS and MCS. Our results showed that the PCS score in the ALD-R group was significantly lower than published Japanese norms, not only preoperatively but also 12 months after transplantation. However, there was no significant difference in MCS score at any time. Previous studies have reported that PCS scores are lowest preoperatively and then gradually recover beginning in the first month 
Table 5 A comparison of ALC-group and NALD-R group at 3 and 12 months after liver transplantation

\begin{tabular}{|c|c|c|c|c|c|c|}
\hline \multirow[t]{4}{*}{ Variables } & \multicolumn{3}{|c|}{3 months after liver transplantation } & \multicolumn{3}{|c|}{12 months after liver transplantation } \\
\hline & ALD-R & NALD-R & $p$ & ALD-R & NALD-R & $p$ \\
\hline & $\mathrm{n}=3$ & $\mathrm{n}=\mathbf{2 8}$ & & $\mathrm{n}=3$ & $\mathrm{n}=\mathbf{2 5}$ & \\
\hline & Mean \pm SD & Mean \pm SD & & Mean \pm SD & Mean \pm SD & \\
\hline AUDIT & $0.00 \pm 0.00$ & $0.46 \pm 1.25$ & 0.54 & $0.00 \pm 0.00$ & $0.33 \pm 1.27$ & 0.66 \\
\hline $\operatorname{HADS}(T)$ & $3.67 \pm 3.22$ & $9.46 \pm 7.31$ & 0.19 & $2.00 \pm 2.65$ & $7.64 \pm 7.33$ & 0.20 \\
\hline $\mathrm{BDI}$ & $8.67 \pm 7.51$ & $9.52 \pm 8.03$ & 0.86 & $4.67 \pm 4.04$ & $8.68 \pm 7.66$ & 0.39 \\
\hline BEMIB & $33.33 \pm 4.16$ & $31.79 \pm 4.34$ & 0.56 & $34.00 \pm 3.46$ & $34.09 \pm 3.04$ & 0.96 \\
\hline \multicolumn{7}{|l|}{ SSQ } \\
\hline NP & $9.50 \pm 6.30$ & $4.67 \pm 3.52$ & 0.04 & $5.06 \pm 1.01$ & $4.35 \pm 2.08$ & 0.57 \\
\hline SR & $5.67 \pm 0.58$ & $5.06 \pm 1.06$ & 0.35 & $5.08 \pm 0.12$ & $5.17 \pm 0.93$ & 0.89 \\
\hline \multicolumn{7}{|l|}{$S F-36$} \\
\hline PCS & $17.47 \pm 28.25$ & $26.03 \pm 16.63$ & 0.47 & $37.42 \pm 10.93$ & $43.80 \pm 12.55$ & 0.41 \\
\hline MCS & $57.33 \pm 14.03$ & $54.22 \pm 9.91$ & 0.62 & $58.65 \pm 6.77$ & $53.77 \pm 9.31$ & 0.39 \\
\hline
\end{tabular}

Bold value indicate $p<0.05$

ALD-RC, Alcoholic Liver Disease Recipient Candidate; AUDIT, Alcohol Use Disorders Identification Test; BDI, Beck Depression Inventory; BEMIB, Brief Evaluation of Medication Influences and Beliefs; HADS, Hospital Anxiety and Depression Scale; NALD-RC, Non-Alcoholic Liver Disease Recipient Candidate; SF-36, The Medical Outcomes Study 36-item short form Health Survey (PCS, Physical Component Summary; MCS, Mental Component Summary); SSQ, Social Support Questionnaire (NP, Number of Persons; SR, Satisfaction Rating)

Comparison of SF-36 scores in ALD-R group and published Japanese norms

$$
\square \text { PCS ALD-R group } \quad \square \text { PCS publised Japanese norms }
$$$$
\square \text { MCS ALD-R group } \quad \square \text { MCS publised Japanese norms }
$$

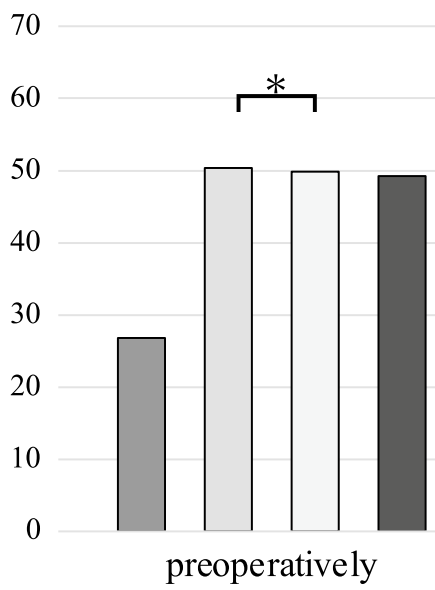

preoperatively

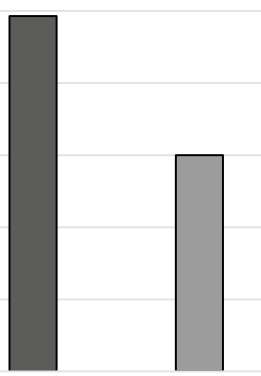

3 months

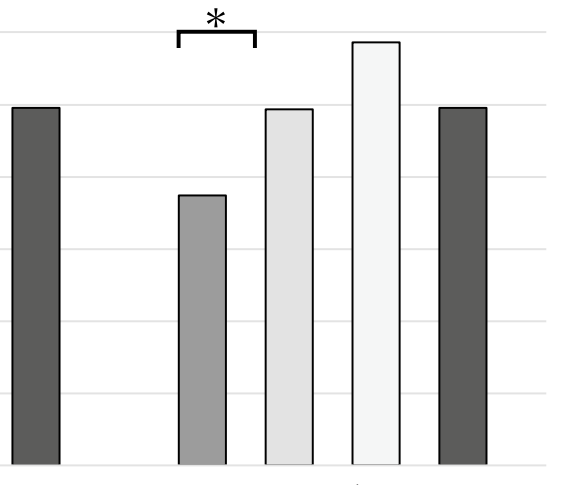

12 months

Time (months)

$$
* \mathrm{P}<0.05
$$

Fig. 2 Comparison of SF-36 scores in ALD-R group and published Japanese norms. Although PCS scores in ALD-R were significantly lower than published Japanese norms preoperatively and at 12 months after transplantation, there was no significant difference in MCS scores at any time. ALD-R: Alcoholic liver disease recipient; MCS: Mental component summary; PCS: Physical component summary; SF-36: Short Form Health Survey

after transplantation, and that MCS scores recover rapidly beginning 1 month after transplantation [47, 48]. Our results are similar in that we also found that PCS and MCS scores gradually recovered from 3 months after transplantation.
Our study has several limitations. One study limitation is that we did not directly compare the psychosocial characteristics of ALD-RC and alcohol-dependent patients; therefore, further research is needed. Another limitation is that this research was a single-institution prospective observational study using data on a small group of 
patients. The number of patients who underwent liver transplantation was especially small (ALD-R: 3,3 and NALD-R: 28, 25 in 3 and 12 months after liver transplantation, respectively), therefore, we could not draw definitive conclude whether the psychosocial characteristics of ALD-R and NALD-R are really similar, and we did not examine whether our results are unique to our institution or similar in other institutions or countries. Future multicenter collaborative research is needed to investigate these issues. In addition, we should also consider that the alcohol abstinence rule has changed from March 2014, that is, the 6-month or 18-month abstinence rule. This change might affect the number of patients who received liver transplantation or the results in this study.

\section{Conclusion}

The psychosocial characteristics of ALD-RC and NALD$\mathrm{RC}$ may be similar when evaluated on the basis of the abstinence rule. This result also implies that the psychosocial characteristics of ALD-RC may differ from the previously reported psychosocial characteristics of alcohol-dependent patients. These important findings indicate that we must appropriately evaluate both ALD-RC and NALD-RC, and our results have the potential to provide helpful information for the evaluation of ALD-RC.

\section{Availability of data and materials}

The datasets used and analyzed during the current study are available only upon request, as the data contain potentially identifying or sensitive psychosocial information(alcohol abuse, childhood experience, personality trait, history of psychiatric disorders and so on). All the data supporting our findings are contained within the manuscript.

\section{Declarations}

\section{Ethics approval and consent to participate}

The study protocol was performed in accordance with the Declaration of Helsinki and was approved by the ethics review committee of Nagoya University Graduate School of Medicine (Approval No. 2012-0339) and all participants provided written informed consent to take part in the study.

\section{Consent for publication}

We obtained the consent from for publication from all participants. We can present these consent form if editors request.

\section{Competing interests}

The authors declare that they have no competing interests.

\section{Author details}

${ }^{1}$ Department of Transplantation Surgery, Nagoya University Hospital, 65 Tsurumai-cho, Showa-ku, Nagoya 466-8560, Japan. ²Department of Transplantation and Endocrine Surgery (Surgery II), Nagoya University Graduate School of Medicine, 65 Tsurumai-cho, Showa-ku, Nagoya 466-8550, Japan. ${ }^{3}$ Department of Psychiatry, Nagoya University Graduate School of Medicine, 65 Tsurumai-cho, Showa-ku, Nagoya 466-8550, Japan. ${ }^{4}$ Transplant Coordination Service, Nagoya University Hospital, 65 Tsurumai-cho, Showa-ku, Nagoya 466-8560, Japan.

Received: 23 March 2021 Accepted: 17 November 2021

Published online: 29 November 2021

\begin{abstract}
Abbreviations
ALD: Alcoholic liver disease; LT: Liver transplantation; ALD-R: ALD recipients; ALD-RC: ALD recipient candidates; NALD-R: Non-ALD recipients; NALDRC: Non-ALD recipient candidates; SSQ: Social Support Questionnaire; NP: Number of Persons; SR: Satisfaction Rating; PBI: Parental Bonding Instrument; SF-36: The Medical Outcomes Study 36-Item Short Form Health Survey; PCS: Physical Component Summary; MCS: Mental Component Summary; VAS: Visual Analogue Scale; AUDIT: Alcohol Use Disorders Identification Test; HADS: Hospital Anxiety and Depression Scale; BDI: Beck Depression Inventory; BEMIB Brief Evaluation of Medication Influences and Beliefs; TCI:Temperament and Character Inventory.
\end{abstract}

\section{Acknowledgements \\ We sincerely thank the patients for their cooperation in this study. We also thank Yasuharu Onishi, MD, PhD (Department of Transplant Surgery, Jichi Medical University Hospital) for entry assistance. We thank Masahiko Ando, MD, PhD and Fumie Kinoshita (Date Coordinating Center, Department of Advanced Medicine, Nagoya University Hospital, Nagoya, Japan) for conduct- ing the statistical review. We thank Diane Williams, PhD, from Edanz Group (https://en-author-services.edanzgroup.com/ac), for editing a draft of this manuscript.}

\section{Authors' contributions}

SM and $\mathrm{KIH}$ contributed equally to this work of participating in designing the research, performing data collection, performing data analysis, and writing the article; KS and TT participated in data collection and assisted with data analysis; KN, JK, YA, TC, YN, KM, KK, YM, KE and IK participated in data collection; $\mathrm{KAH}$ assisted with data analysis and contributed to writing the article; ON provided academic opinions on psychiatry and supervised this research; OY helped supervised the study and critically revised the manuscript. All authors read and approved the final manuscript.

\section{Funding}

None.

\section{References}

1. Obed A, Stern S, Jarrad A, Lorf T. Six month abstinence rule for liver transplantation in severe alcoholic liver disease patients. World J Gastroenterol. 2015;21(14):4423-6.

2. Egawa H, Ueda Y, Kawagishi N, Yagi T, Kimura H, Ichida T. Significance of pretransplant abstinence on harmful alcohol relapse after liver transplantation for alcoholic cirrhosis in Japan. Hepatol Res. 2014;44(14):E428-36.

3. Addolorato G, Mirijello A, Leggio L, Ferrulli A, D'Angelo C, Vassallo G, Cossari A, Gasbarrini G, Landolfi R, Agnes S, et al. Liver transplantation in alcoholic patients: impact of an alcohol addiction unit within a liver transplant center. Alcoholism (NY). 2013;37(9):1601-8.

4. Mathurin P, Moreno C, Samuel D, Dumortier J, Salleron J, Durand F, Castel $H$, Duhamel A, Pageaux GP, Leroy V, et al. Early liver transplantation for severe alcoholic hepatitis. N Engl J Med. 2011;365(19):1790-800.

5. Choudhary NS, Kumar N, Saigal S, Rai R, Saraf N, Soin AS. Liver transplantation for alcohol-related liver disease. J Clin Exp Hepatol. 2016;6(1):47-53.

6. Marroni CA, Fleck AD, Fernandes SA, Galant LH, Mucenic M, Meine MHD, Mariante-Neto G, Brandao ABD. Liver transplantation and alcoholic liver disease: history, controversies, and considerations. World J Gastroenterol. 2018;24(26):2785-805.

7. Anantharaju A, Van Thiel DH. Liver transplantation for alcoholic liver disease. Alcohol Res Health. 2003;27(3):257-68.

8. Mellinger JL, Volk ML. Transplantation for alcohol-related liver disease: is it fair? Alcohol Alcohol. 2018;53(2):173-7.

9. Bodingbauer M, Wekerle T, Pakrah B, Roschger P, Peck-Radosavljevic M, Silberhumer G, Grampp S, Rockenschaub S, Berlakovich G, Steininger R, et al. Prophylactic bisphosphonate treatment prevents bone fractures after liver transplantation. Am J Transplant. 2007;7(7):1763-9.

10. Onishi Y, Kimura H, Hori T, Kishi S, Kamei H, Kurata N, Tsuboi C, Yamaguchi N, Takahashi M, Sunada S, et al. Risk of alcohol use relapse after liver transplantation for alcoholic liver disease. World J Gastroenterol. 2017;23(5):869-75. 
11. Moos RH, Moos BS. Rates and predictors of relapse after natural and treated remission from alcohol use disorders. Addiction. 2006;101(2):212-22

12. Connor JP, Haber PS, Hall WD. Alcohol use disorders. The Lancet. 2016:387(10022):988-98.

13. Berlakovich $G A$. Challenges in transplantation for alcoholic liver disease. World J Gastroenterol. 2014;20(25):8033-9.

14. Rustad JK, Stern TA, Prabhakar M, Musselman D. Risk factors for alcohol relapse following orthotopic liver transplantation: a systematic review. Psychosomatics. 2015;56(1):21-35.

15. Testino G. Alcohol use disorder, liver transplantation and ethics. Bioethics. 2017;31(5):418-9.

16. Lucey MR. Liver transplantation in patients with alcoholic liver disease. Liver Transpl. 2011;17(7):751-9.

17. Umeshita K, Inomata Y, Furukawa H, Kasahara M, Kawasaki S, Kobayashi E, Kokudo N, Sakisaka S, Shimada M, Tanaka E, et al. Liver transplantation in Japan: registry by the Japanese Liver Transplantation Society. Hepatol Res. 2016;46(12):1171-86.

18. Umeshita K, Eguchi S, Egawa H, Haga H, Kasahara M, Kokudo N, Sakisaka S, Takada Y, Tanaka E, Eguchi H, et al. Liver transplantation in Japan: registry by the Japanese Liver Transplantation Society. Hepatol Res. 2019;49(9):964-80.

19. Fukuhara SSY, Bito S, Kurokawa K. Manual of SF-36 Japanese version 1.2. Tokyo: Public Health Research Foundation; 2001.

20. Fukuhara S, Bito S, Green J, Hsiao A, Kurokawa K. Translation, adaptation, and validation of the SF-36 Health Survey for use in Japan. J Clin Epidemiol. 1998;51(11):1037-44.

21. Fukuhara S, Ware JE, Kosinski M, Wada S, Gandek B. Psychometric and clinical tests of validity of the Japanese SF-36 Health Survey. J Clin Epidemiol. 1998;51(11):1045-53.

22. Huskisson EC. Measurement of pain. Lancet. 1974;2(7889):1127-31.

23. McCormack HM, Horne DJD, Sheather S. Clinical-applications of visual analog scales - a critical-review. Psychol Med. 1988;18(4):1007-19.

24. Saunders JB, Aasland OG, Babor TF, Delafuente JR, Grant M. Development of the alcohol-use disorders identification test (AUDIT) — who collaborative project on early detection of persons with harmful alcohol-consumption, 2. Addiction. 1993;88(6):791-804.

25. Zigmond AS, Snaith RP. The hospital anxiety and depression scale. Acta Psychiatr Scand. 1983;67(6):361-70.

26. Kugaya A, Akechi T, Okuyama T, Okamura H, Uchitomi Y. Screening for psychological distress in Japanese cancer patients. Jpn J Clin Oncol. 1998;28(5):333-8.

27. Beck AT, Erbaugh J, Ward CH, Mock J, Mendelsohn M. An inventory for measuring depression. Arch Gen Psychiatry. 1961;4(6):561-70.

28. Cavanaugh S, Clark DC, Gibbons RD. Diagnosing depression in the hospitalized medically ill. Psychosomatics. 1983;24(9):809-15.

29. Tatsuya T. Reliability and validity of the Japanese version of BEMIB modified for patients with bipolar disorder: a self-rating scale for medication adherence. Clin Neuropsychopharmacol Ther. 2013;3:26-32.

30. Sarason IG, Levine HM, Basham RB, Sarason BR. Assessing social support-the social support questionnaire. J Pers Soc Psychol. 1983;44(1):127-39.

31. Furukawa TA, Harai H, Hirai T, Kitamura T, Takahashi K. Social Support Questionnaire among psychiatric patients with various diagnoses and normal controls. Soc Psychiatry Psychiatr Epidemiol. 1999;34(4):216-22.
32. Cloninger CR, Svrakic DM, Przybeck TR. A psychobiological model of temperament and character. Arch Gen Psychiatry. 1993;50(12):975-90.

33. Cloninger CR. The temperament and character inventory (TCl): a guide to its development and use. Seattle, WA: Center for Psychobiology of Personality, Washington University; 1994.

34. Kijima N, Tanaka E, Suzuki N, Higuchi H, Kitamura T. Reliability and validity of the Japanese version of the temperament and character inventory. Psychol Rep. 2000;86(3):1050-8.

35. Parker G, Tupling H, Brown LB. Parental bonding instrument. Br J Med Psychol. 1979;52(MAR):1-10.

36. Kitamura T, Psych FRC, Suzuki T. A validation-study of the parental bonding instrument in a Japanese population. Jpn J Psychiatry Neurol. 1993:47(1):29-36.

37. Ware JE. The SF-36 health survey. In: Spilker B, editor. Quality of life and pharmacoeconomics in clinical trials. 2nd ed. Philadelphia: LippincottRaven; 1996. p. 337-45.

38. Rae AM, Joyce PR, Luty SE, Mulder RT. The effect of a history of alcohol dependence in adult major depression. J Affect Disord. 2002;70(3):281-90.

39. Rambau S, Forstner AJ, Wegener I, Mucke M, Wissussek CTS, Staufenbiel SM, Geiser F, Schumacher J, Conrad R. Childhood adversities, bonding, and personality in social anxiety disorder with alcohol use disorder. Psychiatry Res. 2018;262:295-302.

40. Dube SR, Anda RF, Felitti VJ, Edwards VJ, Croft JB. Adverse childhood experiences and personal alcohol abuse as an adult. Addict Behav. 2002;27(5):713-25.

41. La Flair LN, Reboussin BA, Storr CL, Letourneau E, Green KM, Mojtabai R, Pacek LR, Alvanzo AAH, Cullen B, Crum RM. Childhood abuse and neglect and transitions in stages of alcohol involvement among women: a latent transition analysis approach. Drug Alcohol Depend. 2013;132(3):491-8.

42. Magnusson A, Lundholm C, Goransson M, Copeland W, Heilig M, Pedersen NL. Familial influence and childhood trauma in female alcoholism. Psychol Med. 2012;42(2):381-9.

43. DiMartini A, Dew MA, Javed L, Fitzgerald MG, Jain A, Day N. Pretransplant psychiatric and medical comorbidity of alcoholic liver disease patients who received liver transplant. Psychosomatics. 2004;45(6):517-23.

44. Trief PM, Jiang Y, Beck R, Huckfeldt PJ, Knight T, Miller KM, Weinstock RS. Adults with type 1 diabetes: partner relationships and outcomes. J Health Psychol. 2017;22(4):446-56.

45. Roebuck A, Furze G, Thompson DR. Health-related quality of life after myocardial infarction: an interview study. J Adv Nurs. 2001;34(6):787-94.

46. The Japan Society for Transplantation. http://www.asas.or.jp/jst/general/ number/

47. Onghena L, Develtere W, Poppe C, Geerts A, Troisi R, Vanlander A, Berrevoet $F$, Rogiers $X$, Van Vlierberghe $H$, Verhelst $X$. Quality of life after liver transplantation: state of the art. World J Hepatol. 2016;8(18):749-56.

48. Telles-Correia D, Barbosa A, Mega I, Mateus E, Monteiro E. When does quality of life improve after liver transplantation? A longitudinal prospective study. Transplant Proc. 2009:41(3):904-5.

\section{Publisher's Note}

Springer Nature remains neutral with regard to jurisdictional claims in published maps and institutional affiliations.

Ready to submit your research? Choose BMC and benefit from

- fast, convenient online submission

- thorough peer review by experienced researchers in your field

- rapid publication on acceptance

- support for research data, including large and complex data types

- gold Open Access which fosters wider collaboration and increased citations

- maximum visibility for your research: over 100M website views per year

At BMC, research is always in progress.

Learn more biomedcentral.com/submissions 